\section{Avaliação do envelhecimento natural e de tratamentos superficiais ecológicos em rebocos de terra}

\section{Assessment of natural aging and ecological surface treatments in earth renders}

\author{
TÂNIA SANTOS ${ }^{1 *}$ \\ RICARDO GOMES ${ }^{2}$ \\ PAULINA FARIA $^{1}$ \\ 1. CERIS - Civil Engineering \\ Research and Innovation for \\ Sustainability e Departamento \\ de Engenharia Civil, \\ Universidade NOVA de Lisboa, \\ Caparica, Portugal \\ 2. Departamento de \\ Engenharia Civil, \\ Universidade NOVA de Lisboa, \\ Caparica, Portugal \\ *tr.santos@campus.fct.unl.pt
}

\begin{abstract}
Resumo
Em conservação, os rebocos de terra podem ser utilizados como camadas de sacrifício. No entanto, a terra é vulnerável quando em contacto com a água. A aplicação de tratamentos superficiais ecológicos em rebocos de terra pode aumentar a sua durabilidade, ecoeficiência e gama de aplicações. Neste artigo avaliou-se o comportamento de um reboco de argamassa pré-doseada de terra aplicado in situ sobre muretes experimentais de alvenarias de adobe e de blocos de betão (em exposição exterior com proteção), e em condições controladas de laboratório, sobre tijolo furado, após um período de quatro anos de envelhecimento. Foram aplicados diversos tratamentos superficiais sobre os rebocos: óleo de linhaça, mucilagem de aloé vera e água da cozedura de massa e de arroz. Os rebocos foram caracterizados de forma não destrutiva. O tratamento superficial com óleo de linhaça apresenta bons resultados e melhora a durabilidade do reboco, conferindo-lhe adequada protecção contra a degradação natural.
\end{abstract}

\begin{abstract}
In conservation, earth renders can be used as sacrificial coatings. However, earth presents vulnerability when in contact with water. The application of ecological surface treatments on earth renders can be of great relevance, ensuring their durability while increasing ecoefficiency and extending its range of applications. The behaviour of a ready-mixed earth render applied in situ, on adobe and concrete block masonry experimental walls exposed outdoors with protection, and under controlled laboratory conditions, on hollow bricks, was evaluated after four years. Several superficial treatments were applied on the renders: linseed oil, mucilage of aloe vera and pasta and rice cooking water. The renders were characterized by non-destructive tests. The surface treatment with linseed oil presents good results and improves the durability of the earth render, giving it adequate protection against natural degradation.
\end{abstract}

\section{PALAVRAS-CHAVE}

Argamassa

Caracterização in situ

Durabilidade

Exposição natural

Revestimento

Terra argilosa

\section{KEYWORDS}

Mortar

In situ characterisation

Durability

Natural exposure

Clayish earth

Coating 


\section{Introdução}

A terra tem vindo a ser utilizada como material de construção desde a pré-história [1-3]. É composta por diferentes proporções e tipos de argilas, siltes, areias e gravilhas, e resulta da meteorização de rochas. Está disponível em praticamente todas as regiões do mundo, aplicada em tecnologias construtivas como o tabique, a taipa, a alvenaria de adobe e, mais recentemente, de blocos de terra comprimida, entre muitas outras tecnologias, como os rebocos. Assume assim um carácter claramente universal. Apesar da utilização da terra ser muitas vezes associada a construções de pequeno porte, erigidas com escassez de recursos financeiros, podem também ser encontradas paredes de terra e aplicações de argamassas deste tipo de material em construções históricas e culturais como palácios, igrejas, mosteiros e muralhas [4].

A utilização de argamassas de cimento em construções de terra ou de alvenaria de pedra argamassada é propensa a provocar problemas a estas construções devido à diferente deformabilidade dos materiais e à dificuldade da migração do vapor de água [5-6]. Assim, torna-se de extrema importância a utilização e constante desenvolvimento de argamassas para reparação e para rebocos de protecção e sacrifício, que sejam compatíveis com estas construções, de modo a poderem serem aplicadas na sua manutenção, contribuindo efectivamente para a sua durabilidade. Os rebocos de argamassas de terra asseguram compatibilidade com este tipo de construções.

As argamassas de terra foram aplicadas no assentamento de alvenarias com blocos à base de terra ou de pedra, e em revestimentos de paredes, em rebocos, ou mesmo de pavimentos. A sua aplicação tem sido contínua em muitos países. Nos países mais desenvolvidos, estas argamassas foram correntemente aplicadas até meados do século XX, tendo então caído em desuso. Nestes países o interesse pelos rebocos de argamassa de terra ressurgiu principalmente no século XXI devido a inúmeras vantagens conferidas pela terra face a outro tipo de rebocos: a sua abundância e facilidade de obtenção; o facto de ser reutilizável (desde que não quimicamente estabilizada); reciclável e incombustível, embora não renovável [7-8]. Ao contrário do cimento e da cal, a terra não necessita de calcinação, grandes processos de transformação e distâncias de transporte, podendo ser muitas vezes utilizadas terras escavadas das próprias fundações de construções e outras terras locais [5]. Apresenta assim uma reduzida emissão de $\mathrm{CO}_{2}$ e um ciclo de vida caracterizado por um baixo impacto ambiental e energético $[2,9]$. No entanto, os rebocos de terra apresentam também vulnerabilidades, como seja no contacto com a água, quando não são estabilizados quimicamente ou protegidos.

Quando utilizados no interior, os rebocos de terra contribuem para a regulação e equilíbrio da humidade do ar interior, contribuindo para o conforto dos utilizadores e qualidade do ar interior, devido à elevada capacidade higroscópica da argila [2, 9-17].
Existem diversos estudos relativos a argamassas de terra para aplicação no interior [11, 18-20]. No entanto, devido à vulnerabilidade das argamassas de terra quando em contacto com água, desaconselha-se a sua utilização no exterior não protegido ou em zonas húmidas interiores, sem a aplicação de qualquer tipo de proteç̧ão ou estabilização [17]. Apesar de existirem alguns estudos sobre a aplicação dos rebocos de terra no interior, existem poucos trabalhos sobre a durabilidade deste tipo de reboco quando em contacto com a água e em condições de exposição agressiva [5-6, 21].

A aplicação de tratamentos de superfície pode ser uma alternativa para melhorar as características das argamassas de terra aplicadas no exterior [22] ou, em zonas interiores húmidas ou com possibilidade de contacto com água (por exemplo sob uma janela, que pode ter sido deixada aberta em situação de chuva ou perto de um lavatório). Pode também possibilitar o alargamento do campo de aplicação de rebocos de terra quer em suportes antigos, como a pedra argamassada, quer em suportes recentes, como as alvenarias de blocos de betão e de tijolo furado [20-21]. Este último aspecto pode ser particularmente importante para a conservação e a durabilidade de rebocos de terra expostos, por exemplo, em sítios arqueológicos - rebocos históricos ou utilizados para proteç̧ão sacrificial dos vestígios existentes [23].

A caiação e os barramentos são tratamentos superficiais tradicionalmente utilizados na construção com terra. De forma a manter as vantagens ecológicas dos rebocos de terra, podem ser utilizados diversos produtos naturais para produzir produtos para tratamentos superficiais, também eles ecológicos, para proteger este tipo de rebocos. Os cactos, o agave, as algas, a farinha de trigo, a manteiga de karité e a caseína, entre outros, são exemplos de produtos naturais que podem ser utilizados como tratamentos superficiais ecológicos [24]. Em estudos anteriores, a utilização do óleo de linhaça foi avaliada como adjuvante de rebocos de terra [25], assim como a utilização de mucilagens de plantas, como é o caso da aloé vera [26]. Vissac et al. [24] refere também a utilização do óleo de linhaça e a mucilagem de aloé vera como tratamentos superficiais de argamassas de terra. Por transmissão oral recolheu-se que a água da cozedura de arroz ou a água em que o arroz é demolhado, é por vezes utilizada como tratamento superficial tradicional de construções com terra na República Popular da China.

No presente estudo avaliou-se o comportamento de uma argamassa pré-doseada envelhecida durante um período de quatro anos, aplicada como reboco sobre muretes experimentais exteriores de alvenaria de adobe e de blocos de betão (simulando um suporte antigo e um recente), protegidos da chuva incidente através de um telheiro, e em laboratório em provetes de reboco sobre tijolo furado. Após quatro anos de exposição natural dos rebocos, aplicaram-se tratamentos superficiais ecológicos e as suas características foram de novo avaliadas através da realização de ensaios in situ. 


\section{Argamassas, tratamentos superficiais e métodos de ensaio}

\section{Muretes, argamassa e tratamentos de superfície}

$\mathrm{Na}$ Estação Experimental em Exposição Natural de Alvenarias e Revestimentos da FCT NOVA, localizada no Monte da Caparica, aproximadamente a $3 \mathrm{~km}$ da costa Atlântica e do estuário do rio Tejo, realizaram-se dois muretes experimentais de alvenarias de adobe e de blocos de betão, respectivamente com 1,30 $\mathrm{m} \times 1,90 \mathrm{~m} \times 0,15 \mathrm{~m}$ e $1,80 \mathrm{~m} \times 2,20 \mathrm{~m} \times 0,20 \mathrm{~m}$ (altura $\times$ comprimento $\times$ espessura). Os adobes utilizados têm dimensões de $0,30 \mathrm{~m}$ $\times 0,06 \mathrm{~m} \times 0,15 \mathrm{~m}$ e os blocos de betão têm 0,50 $\mathrm{m} \times 0,20 \mathrm{~m} \times$ $0,20 \mathrm{~m}$. Argamassas de terra e de cimento foram utilizadas no assentamento das alvenarias de adobe e de blocos de betão, com espessuras de 1,0 e 1,5 cm, respectivamente. Os muretes foram assentes numa sapata de betão simples, sem corte de capilaridade, e expostos a Sul, tal como ilustrado na Figura 1a, e a Norte. A chuva incidente é maioritariamente proveniente de Sul. As alvenarias foram caracterizadas quanto à sua capacidade de absorção de água sob baixa pressão por tubos de Karsten [21], tendo sido demonstrado que a alvenaria de blocos de betão apresenta uma absorção muito elevada comparativamente à de adobe. Três meses após a sua execução, os muretes foram cobertos por um telheiro, para redução da incidência directa da chuva [21].

Após três meses da sua execução foi preparada e aplicada uma argamassa pré-doseada de terra, como reboco da face exposta a Norte dos dois muretes experimentais. Aargamassa pré-doseada ilustrada na Figura ib, é comercializada pela empresa EMBARRO, e constituída por uma terra argilosa ilítica, areia de dimensão máxima de $2 \mathrm{~mm}$ e fibras naturais de aveia com dimensões de 1,0-2,0 cm. Esta argamassa foi utilizada e caracterizada em estudos anteriores [18, 21]. A baridade do material da argamassa, avaliada no estado seco com base na norma NP EN 1097-3 [27], é de 1,17 $\pm 0,01 \mathrm{~kg} / \mathrm{dm}^{3}$ [18]. As análises granulométricas e por difracção de raios-X da argamassa pré-doseada de terra foram apresentadas por Faria et al. [18] e Santos et al. [21]. A argamassa foi preparada in situ e directamente projectada nos dois muretes, tendo sido depois apertada e regularizada através de uma régua
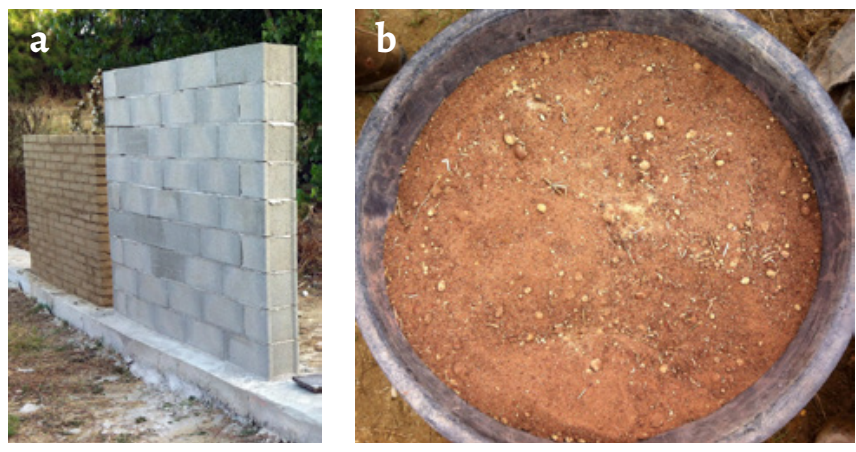

Figura 1. Muretes experimentais sobre sapata antes da aplicação dos rebocos a) e produto pré-doseado para argamassa de reboco $b$ ). de madeira com $2 \mathrm{~m}$, ficando com uma espessura final de $1,5-2,0 \mathrm{~cm}$.

A mesma argamassa foi também aplicada, mas manualmente, sobre tijolo furado, com uma espessura de $1,5 \mathrm{~cm}$, para caracterização em laboratório. Ambos os suportes foram humedecidos antes da aplicação da argamassa. Os provetes em laboratório estiveram em condições de temperatura de $20,0 \pm 2,0{ }^{\circ} \mathrm{C}$ e $65,0 \pm 5,0 \%$ de humidade relativa (HR). Os rebocos estiveram expostos num ambiente semi-rural natural, numa gama de temperaturas de $8,2-27,8^{\circ} \mathrm{C} \mathrm{e}$ 65,0-80,0\% de HR.

Em laboratório, foi avaliada a consistência por espalhamento, a massa volúmica, o teor em ar e o teor em água da argamassa no estado fresco, determinados em estudos anteriores [18, 21], e apresentados na Tabela 1.

Tabela 1. Consistência por espalhamento, massa volúmica, teor em ar e teor em água da argamassa pré-doseada analisada [18, 21].

\begin{tabular}{|c|c|c|}
\hline Ensaio & Norma & Resultado \\
\hline $\begin{array}{l}\text { Consistência por } \\
\text { espalhamento }\end{array}$ & EN 1015-3 [28] & $178,8 \pm 2,5 \mathrm{~mm}$ \\
\hline Massa volúmica & EN 1015-6 [29] & $2,03 \mathrm{~kg} / \mathrm{dm}^{3}$ \\
\hline Teor em ar & EN 1015-7 [30] & $2,8 \%$ \\
\hline Teor em água & $\begin{array}{l}\text { Diferença de massa entre a } \\
\text { amostra no estado fresco e } \\
\text { seco da argamassa }\end{array}$ & $20,1 \pm 0,1 \%$ \\
\hline
\end{tabular}

A norma DIN 18947 [31], para rebocos de argamassas de terra não estabilizadas quimicamente, define como mínimo $1,20 \mathrm{~kg} / \mathrm{dm}^{3}$ para a massa volúmica no estado fresco, e recomenda $175,0 \pm 5,0 \mathrm{~mm}$ para a consistência por espalhamento. Foi avaliada a retracção linear desta argamassa em provetes com dimensões de $4,0 \mathrm{~cm} \times 4,0 \mathrm{~cm}$ $\times 16,0 \mathrm{~cm}$, tendo sido obtida uma retracção linear de $0,21 \pm$ $0,08 \%[18,21]$. Este resultado verifica o valor máximo de $3 \%$, definido pela norma DIN 18947 [31] para argamassas de terra com adição de fibras.

Um ano após a aplicação, observou-se a inexistência de fendilhação nos rebocos sobre os muretes experimentais de alvenarias de adobe e de blocos de betão.

Sendo a terra argilosa um produto de origem natural e reutilizável, foram seleccionados tratamentos superficiais para aplicação sobre este tipo de reboco também eles de origem natural, com vista a assegurar a eco-eficiência dos revestimentos. Assim, foram aplicados tratamentos superficiais com óleo de linhaça, da marca Tintinhas, mucilagem de aloé vera e água da cozedura de massa e de arroz. Os tratamentos de superficiais foram aplicados após um período de quatro anos de envelhecimento natural dos rebocos, e após uma ligeira escovagem da superfície com pincel.

O tratamento superficial com mucilagem de aloé vera aplicado nos rebocos foi obtido através da sua extracção das folhas da planta, momentos antes da sua aplicação. A extracção da mucilagem da planta é realizada através do 
corte da folha, abertura e, por aperto, extracção do produto que se encontra no seu interior. A mucilagem foi aplicada directamente sobre o reboco, não tendo sido diluída. As águas de cozedura foram obtidas escorrendo as águas após cozedura de massa e de arroz correntes. Estas águas foram acondicionadas em frigorífico durantes alguns dias antes de serem utilizadas.

Os tratamentos superficiais foram aplicados em faixas de aproximadamente $0,20 \mathrm{~m} \times 1,50 \mathrm{~m}$, com o auxílio de um pincel, numa só camada, tendo secado em condições climatéricas exteriores durante 2-3 semanas. Os rebocos de argamassa de terra foram caracterizados in situ antes e 2-3 semanas após a aplicação e secagem dos tratamentos de superfície.

\section{Métodos de ensaio}

Com vista à caracterização in situ dos rebocos procedeu-se a uma análise visual durante toda a campanha experimental, e à realização dos ensaios de coesão superficial, dureza superficial por durómetro e esclerómetro pendular, resistência ao impacto de uma esfera e velocidade da propagação de ultra-sons (Tabela 2). A análise visual e a caracterização destes rebocos foram também realizadas antes e após a aplicação dos tratamentos superficiais.

Tabela 2. Ensaios realizados, procedimentos de ensaio utilizados e número de medições por reboco.

\begin{tabular}{|c|c|c|}
\hline Ensaio & $\begin{array}{l}\text { Procedimento } \\
\text { de ensaio }\end{array}$ & $\begin{array}{l}\text { Número de medições } \\
\text { por reboco }\end{array}$ \\
\hline Coesão superficial & $\begin{array}{l}\text { Ensaio adaptado [6, } \\
18,21,24,32]\end{array}$ & 5 \\
\hline Durómetro & ASTM D2240-00 [33] & 12 \\
\hline $\begin{array}{l}\text { Esclerómetro } \\
\text { pendular }\end{array}$ & ASTM C805 [34] & 12 \\
\hline $\begin{array}{l}\text { Resistência ao } \\
\text { impacto da esfera }\end{array}$ & $\begin{array}{l}\text { Ficha de ensaio LNEC } \\
\text { Fe } \mathrm{Pa} 25[35]\end{array}$ & 5 \\
\hline Ultra-sons & $\begin{array}{l}\text { Ficha de ensaio LNEC } \\
\text { Fe } \mathrm{Pa} 43 \text { [36] e NP EM } \\
12504-4[37]\end{array}$ & $\begin{array}{l}3 \text { medições por reboco e } \\
3 \text { medições em cada um } \\
\text { dos } 4 \text { pontos de medição }\end{array}$ \\
\hline
\end{tabular}

Na campanha experimental foram avaliados in situ os painéis de reboco aplicados nos muretes de alvenarias de adobe e de blocos de betão. Este último apresentava diferente nível de degradação, analisado visualmente, entre a parte superior e inferior. Esta diferenciação deveu-se à protecção superior aplicada sobre os muretes não impedir, propositadamente, algum contacto da água da chuva com essa área do reboco. Assim, esse reboco foi dividido em duas zonas distintas: reboco pouco degradado (zona superior) e reboco mais degradado (zona inferior). Em laboratório foi avaliado o reboco de argamassa aplicado em provetes sobre tijolo furado.

\section{Avaliação visual}

Foi realizada uma análise visual a características tais como a cor e/ou a sua alteração, fissuração, erosão, destacamento ou perda de aderência do reboco, presença de fibras, desenvolvimento de bolores e degradação dos painéis de reboco após quatro anos de exposição natural exterior coberta.

\section{Coesão superficial}

A coesão de uma argamassa é a força de ligação entre as partículas do material constituinte. A terra argilosa apresenta genericamente uma boa coesão [24]. O ensaio de coesão superficial, definido por Drdácky et al. [32] e adaptado por outros autores [6, 18, 21, 24], consiste na aplicação de rectângulos de fita adesiva, com $50 \times 70 \mathrm{~mm}$ (Figura 2) na superfície do reboco, os quais são pressionados uniformemente, e em seguida retirados. A coesão superficial foi obtida pela perda de massa superficial da argamassa ocorrida durante o ensaio, determinada pela diferença entre a massa do rectângulo de fita adesiva antes e após o ensaio, medidas numa balança de precisão o,001 $\mathrm{g}$.

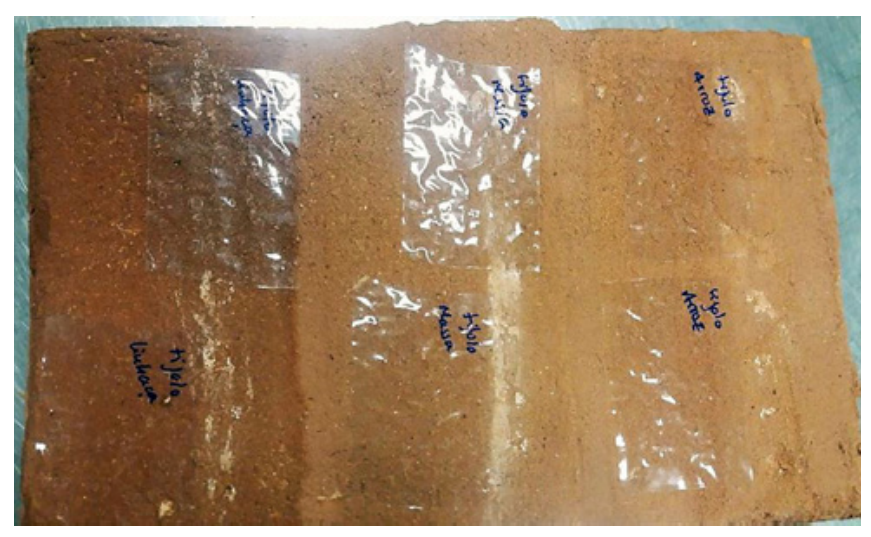

Figura 2. Faixas de fita adesiva sobre os tratamentos de superfície aplicados no reboco de terra sobre o tijolo furado.

\section{Dureza superficial por durómetro e por esclerómetro pendular} $O$ ensaio de dureza superficial por durómetro foi realizado com um durómetro PCE Shore A. O pino localizado na extremidade do aparelho, quando pressionado contra o reboco pela acção da mola, sob carga normalizada, indica a resistência à penetração, que se traduz no movimento de um ponteiro ao longo de uma escala de 0 a 100 [38].

No ensaio de dureza superficial por esclerómetro foi utilizado um esclerómetro de pêndulo Schmidt PT que, através de uma massa conhecida, provoca uma reacção por impulso que choca contra a superfície do revestimento [38]. A quantidade de energia recuperada no ressalto da massa é medida durante o ensaio, obtendo-se o índice de dureza da superfície ensaiada (valor de ressalto) sobre uma escala graduada apresentada no aparelho [38]. Este ensaio foi realizado apenas sobre os rebocos aplicados aos muretes in situ, e não nos provetes sobre tijolo furado, que poderiam ficar danificados devido ao impacto causado. Este ensaio permite ainda avaliar o possível destacamento ou perda de aderência do reboco pelo impacto do esclerómetro. 

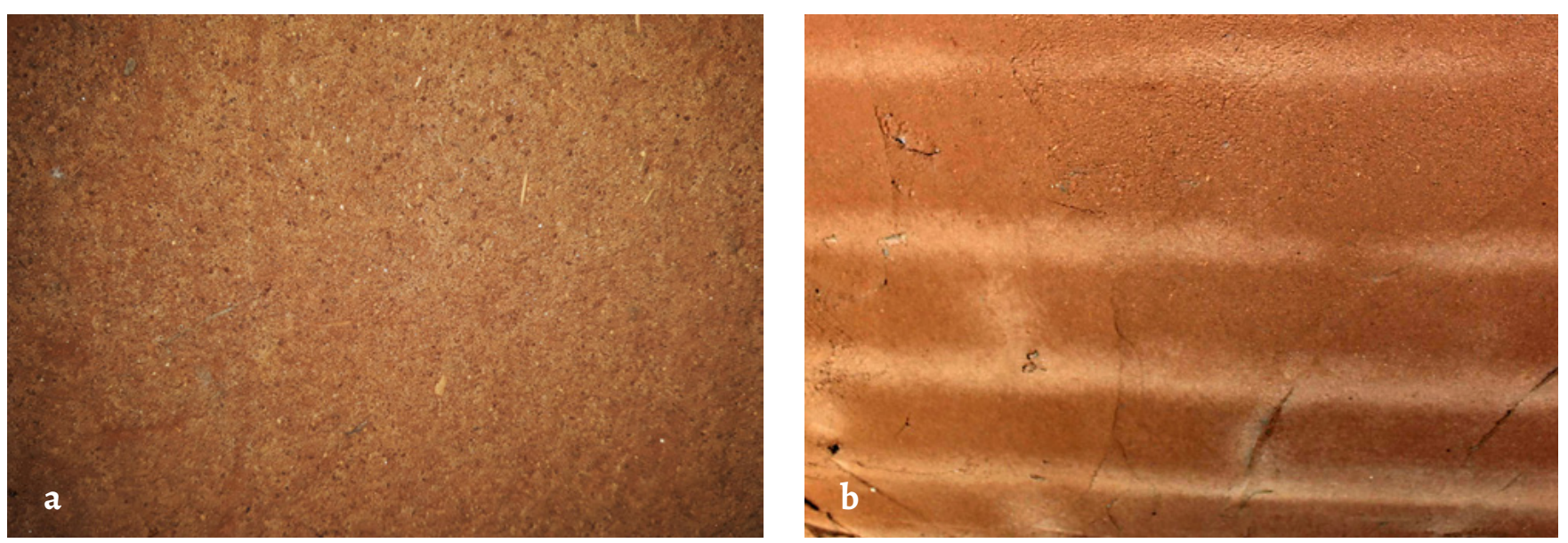

Figura 3. Análise visual do reboco de argamassa pré-doseada de terra a diferentes escalas, no murete de alvenaria de adobe a) e no murete de alvenaria de blocos de betão $b$ ).

\section{Resistência ao impacto da esfera}

O ensaio de resistência ao impacto da esfera pelo equipamento Martinet-Baronnie permite avaliar a capacidade resistente e deformabilidade dos rebocos através do impacto de uma esfera com massa e energia de impacto definidos [6]. Através desse impacto, e de forma mais abrangente que no caso do ensaio anterior, o possível destacamento ou perda de aderência do reboco pode também ser avaliado. O procedimento de ensaio foi baseado em Veiga et al. [39]. A esfera de aço com diâmetro e massa conhecidos [6], foi colocada em posição horizontal na extremidade do braço do aparelho. Em seguida, deixou-se tombar a esfera sobre o reboco de argamassa aplicado sobre cada murete, produzindo um choque com $3 \mathrm{~J}$ de energia sobre o reboco [6, 21]. A degradação na superfície do reboco provocada pelo embate da esfera, foi quantificada pelo diâmetro da concavidade produzida e pela ocorrência de fissuração resultante do impacto [38].

\section{Velocidade de propagação de ultra-sons}

O ensaio de velocidade de propagação de ultra-sons permite avaliar a compacidade do reboco e, consequentemente, a sua porosidade e eventual integridade (incluindo aderência ao suporte). Quanto maior for a velocidade de propagação de ultra-sons, maior será a sua compacidade e integridade, e, consequentemente, menor a sua porosidade. A velocidade de propagação de ultra-sons foi determinada com o aparelho Proceq Pundit Lab. O aparelho é constituído por dois transdutores (emissor e receptor) e um módulo central, que emite ondas ultra-sónicas, e procede à leitura e registo do tempo de transmissão das ondas (em $\mu$ s) [21, 38]. No presente estudo, o método indirecto para a determinação da velocidade de propagação de ultra-sons foi utilizado, no qual o emissor do aparelho é colocado no ponto $0 \mathrm{~cm}$ e o receptor nos pontos $6,8,10$ e $12 \mathrm{~cm}$, ao longo de uma linha recta horizontal [21]. A velocidade de propagação de ultra-sons foi obtida pelo quociente entre a distância entre os transdutores e o tempo de transmissão da onda. A velocidade de propagação dos ultra-sons foi obtida pela média dos valores das quatro distâncias utilizadas nas três medições realizadas em três zonas distintas do reboco.

\section{Resultados}

\section{Avaliação visual}

Analisando a degradação do reboco foi observada uma alteração de cor e alguma rugosidade na superfície das argamassas. Constatou-se que a argamassa de reboco aplicada no murete de alvenaria de adobe não apresentou quaisquer fissuras, mas apenas alguma perda de material que provoca a maior rugosidade referida, ilustrada na Figura 3a. No entanto, no reboco aplicado sobre o murete de blocos de betão foi observada uma fissura de dimensão significativa na zona degradada do reboco. Esta fissura encontra-se na zona de bloco de betão pelo que poderá ser devida a uma possível falta de aperto do reboco nessa zona, uma vez que este apresenta aí, algumas imperfeições.

O reboco aplicado sobre a alvenaria de blocos de betão apresentou degradação apenas na zona inferior onde se verificou a perda de finos devido ao contacto com água. Nessa zona, e tal como demonstrado pela Figura $3 b$, ocorreu também alteração de cor na zona das juntas face à área corrente do reboco. Essa alteração pode ter sido devida à migração de hidróxido de cálcio livre da argamassa de cimento das juntas para a argamassa de reboco, como se uma leve estabilização química tivesse ocorrido [6]. Também poderá ter-se devido às distintas condições de secagem ocorridas entre as áreas de blocos vazados e de argamassa de assentamento.

A presença de fibras naturais é notória na superfície dos rebocos aplicados, sendo, de acordo com a Figura 3, mais evidente no reboco aplicado sobre o murete de alvenaria de adobe, após os quatro anos de exposição.

Os rebocos de argamassa de terra não apresentam qualquer destacamento do suporte nem qualquer desenvolvimento de contaminação biológica. 
Durante a aplicação dos tratamentos de superfície sobre os rebocos de argamassa, foi observada uma alteração de cor da superfície do reboco provocada pela utilização do óleo de linhaça, conferindo-lhe o tom mais escuro visível na Figura 4a. De acordo com a mesma Figura 4, o tratamento de superfície com utilização de mucilagem de aloé vera não apresentou alteração de cor quando aplicado nas superfícies dos rebocos. As águas de cozedura de massa e de arroz não apresentaram alteração de cor sobre a superfície de reboco aplicada no murete de blocos de betão. No entanto, no murete de alvenaria de adobe, foi observada uma ligeira alteração de cor, com pequenos toques amarelados, devido às concentrações de areia na superfície provocadas pela aplicação do tratamento com a utilização do pincel (Figuras 4 e 5).

Após a secagem dos tratamentos de superfície, e tal como demonstrado na Figura 4b, o óleo de linhaça é o único que, de facto, confere uma alteração definitiva de cor à superfície dos rebocos, apresentando um tom mais escuro. As zonas de reboco em que foram aplicados os restantes tratamentos de superfície praticamente regressaram à sua cor original após a sua secagem.

Observou-se a ocorrência de erosão das partículas da superfície dos rebocos apenas durante a aplicação dos tratamentos de superfície por pincelagem, ficando retidas algumas partículas no pincel, tal como demonstrado na Figura 5. Esta erosão é mais evidente na aplicação da mucilagem de aloé vera.
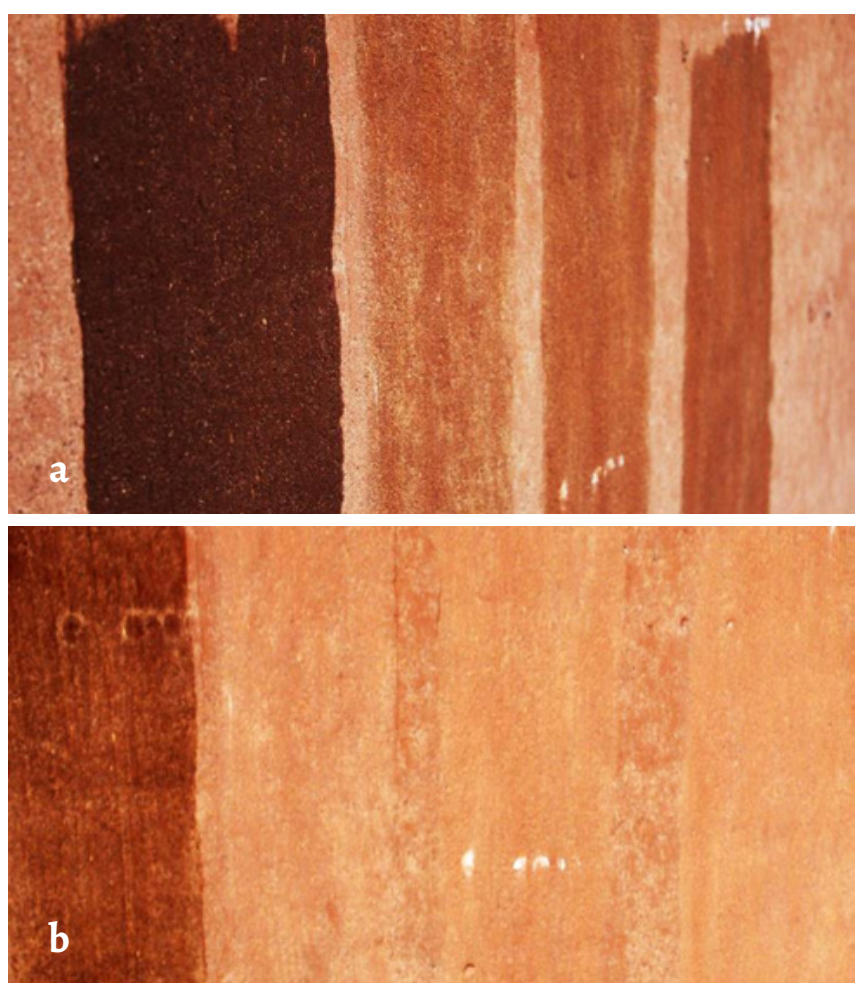

Figura 4. Tratamentos superficiais aplicados no reboco sobre o suporte de alvenaria de adobe, após a aplicação $a$ ) e após a secagem b) (da esquerda para a direita: óleo de linhaça; mucilagem de aloé vera; água da cozedura de massa e água da cozedura de arroz).

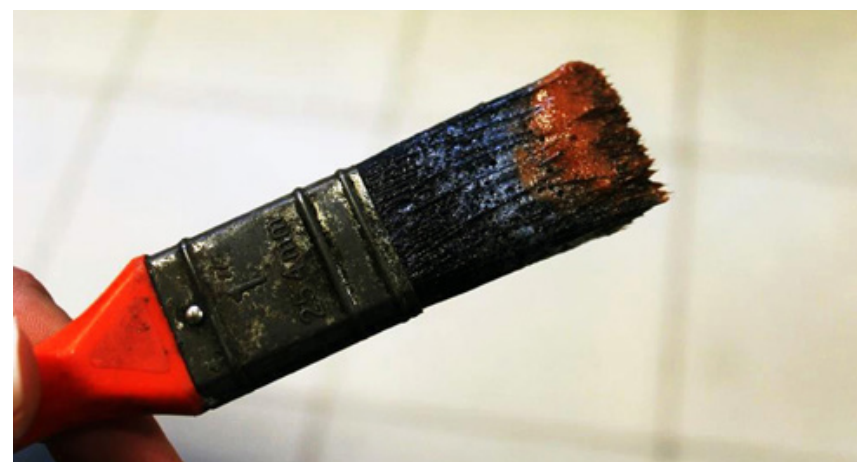

Figura 5. Perda de finos da superfície do reboco devido à aplicação de água da cozedura de massa por pincelagem.

Durante a campanha experimental, manteve-se a inexistência de fissuração após a aplicação de todos os tratamentos superficiais. $\mathrm{O}$ mesmo foi verificado quanto ao destacamento do reboco e ao desenvolvimento de contaminação biológica: não foi observada a presença de qualquer tipo de fungo, bolor ou crescimento de vegetação. A rugosidade e a visualização de algumas fibras mantêm-se após a aplicação de todos os tratamentos e em ambos os suportes. No entanto, a rugosidade do reboco aplicado no murete de alvenaria de adobe com tratamento de superfície de mucilagem de aloé vera apresenta maior rugosidade devido à movimentação de partículas de areia.

\section{Coesão superficial}

Os dados da coesão superficial, valores médios e desvios padrão dos rebocos aplicados nos muretes experimentais e no tijolo furado, em laboratório, obtidos por Faria et al. [18] e Santos et al. [21], todos após um ano de exposição, bem como os valores médios e desvios padrão obtidos no presente estudo, após quatro anos de exposição, antes da aplicação dos tratamentos superficiais, são apresentados na Figura 6, assim como os intervalos de temperatura e HR em que foram realizados os ensaios.

Após a aplicação e secagem dos tratamentos de superfície foram obtidos os resultados de coesão superficial, valores médios e desvios padrão, apresentados na Figura 7, assim como os intervalos de temperatura e HR ocorridos durante a realização do ensaio.

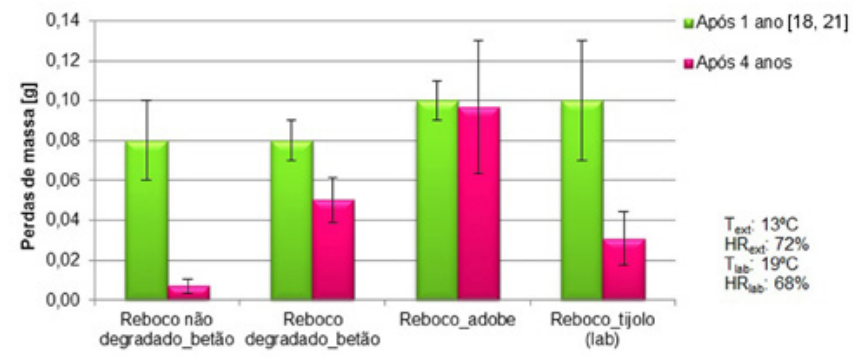

Figura 6. Perda de massa por falta de coesão dos rebocos aplicados nos muretes experimentais e tijolo furado após um ano de exposição [18, 21] e após quatro anos. 


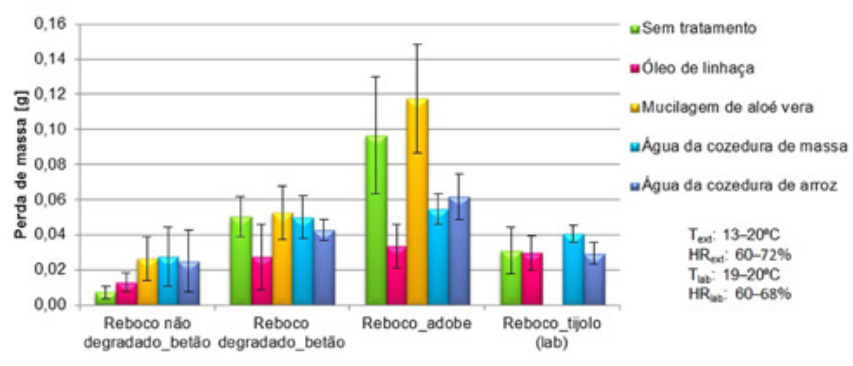

Figura 7. Perda de massa por falta de coesão superficial dos rebocos aplicados nos muretes experimentais e no tijolo furado, imediatamente antes e após a aplicação dos tratamentos superficiais.

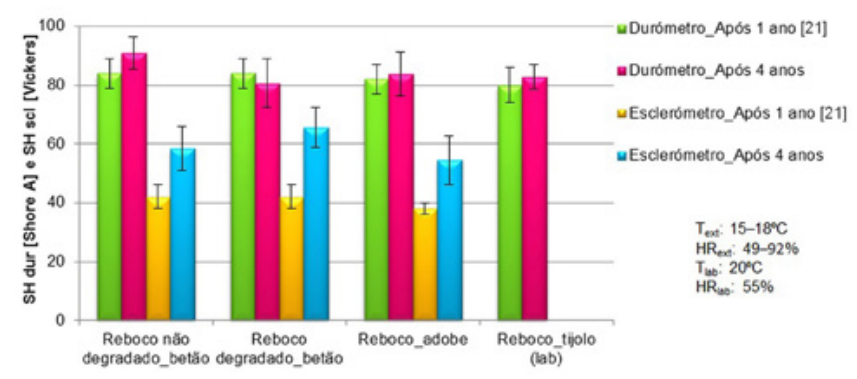

Figura 8. Dureza superficial por durómetro (SH dur) e por esclerómetro ( $\mathrm{SH}$ scl) após um ano de exposição [21] e após quatro anos, imediatamente antes da aplicação dos tratamentos de superfície, nos muretes experimentais e no tijolo furado.

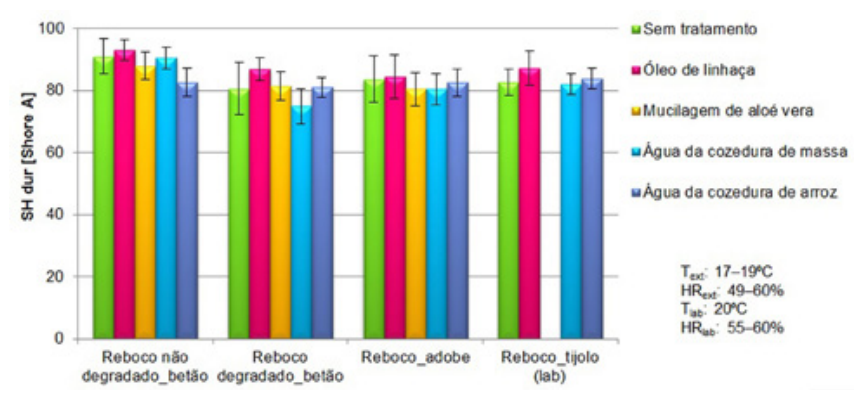

Figura 9. Dureza superficial por durómetro ( $\mathrm{SH}$ dur) nos muretes experimentais e tijolo furado, antes e após a aplicação dos tratamentos superficiais.

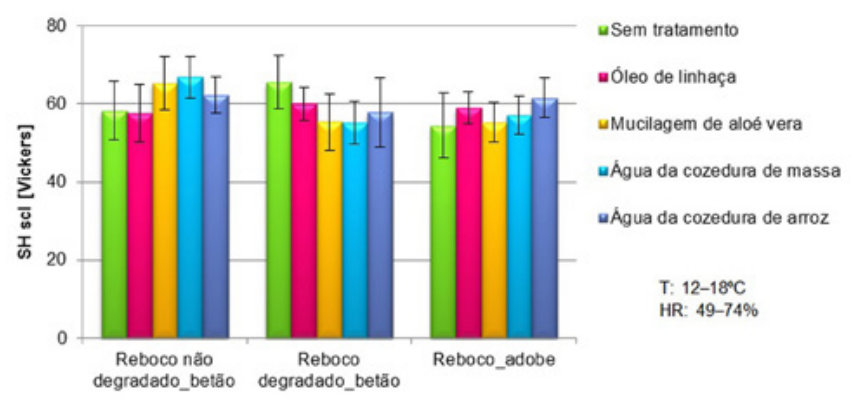

Figura 10. Dureza superficial por esclerómetro ( $\mathrm{SH}$ scl) dos rebocos aplicados nos muretes experimentais, antes e após a aplicação dos tratamentos de superficiais.

\section{Dureza superficial por durómetro e por esclerómetro pendular}

A Figura 8 apresenta os valores médios e desvios padrão da dureza superficial por durómetro e por esclerómetro pendular, nos muretes experimentais e no tijolo furado, em laboratório, após quatro anos de exposição e antes da aplicação dos tratamentos superficiais. Na Figura 8, os resultados obtidos neste estudo são comparados com os obtidos por Santos et al. [21], com um ano de exposição. São ainda apresentados os intervalos de temperatura e HR ocorridos durante a realização do ensaio.

A Figura 9 apresenta os valores médios e desvios padrão da dureza superficial por durómetro obtidos antes e após a aplicação e secagem dos tratamentos superficiais ecológicos nos muretes experimentais e no tijolo furado, em laboratório. Tal como na figura anterior, os intervalos de temperatura e HR ocorridos durante a realização do ensaio são também apresentados.

Os valores médios e desvios padrão de dureza superficial por esclerómetro pedular, após a aplicação e secagem dos tratamentos superficiais, são comparados, na Figura 10, com os valores de dureza superficial por esclerómetro, obtidos antes da aplicação dos tratamentos superficiais. Uma vez mais, os intervalos de temperatura e HR ocorridos durante o ensaio são também apresentados.

\section{Resistência ao impacto da esfera}

Os resultados do ensaio de impacto da esfera pelo equipamento Martinet-Baronnie, média e desvio padrão, após um ano de exposição, obtidos por Santos et al. [21], são comparados na Figura 11, aos valores obtidos no presente estudo, após quatro anos de exposição, antes da aplicação dos tratamentos superficiais.

Quando o diâmetro da concavidade é elevado, mas não ocorre fissuração nem destacamento, significa que o reboco apresenta elevada deformabilidade e boa aderência ao suporte, o que é muito positivo para um reboco. Nenhum dos rebocos analisados apresentou fissuração. Após quatro anos de exposição natural é possível observar um decréscimo da concavidade das argamassas de reboco aplicadas nos muretes experimentais, sendo que o reboco não degradado aplicado sobre o murete de blocos de betão apresenta menor

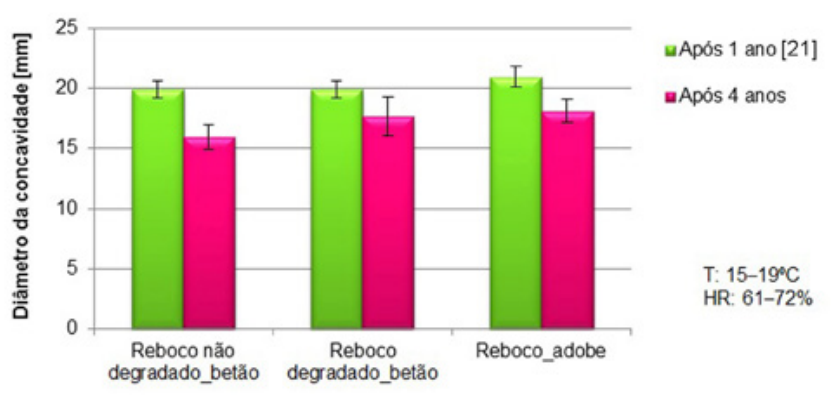

Figura 11. Diâmetro da concavidade provocada pelo impacto da esfera nos rebocos aplicados sobre os muretes experimentais, após um ano de exposição [21] e após quatro anos. 
concavidade quando comparado com os restantes rebocos que se encontram num nível de degradação superior.

$\mathrm{Na}$ Figura 12 são apresentados os valores médios e desvios padrão de diâmetro da concavidade obtidos no ensaio de resistência ao impacto da esfera, realizado imediatamente antes e após a aplicação e secagem dos tratamentos superficiais nos rebocos sobre os muretes experimentais. Os intervalos de temperatura e $\mathrm{HR}$ em que decorreu o ensaio são também apresentados na Figura 12.

\section{Velocidade de propagação de ultra-sons}

Os resultados relativos ao ensaio de velocidade de ultra-sons (valores médios e desvios-padrão), que avalia a compacidade

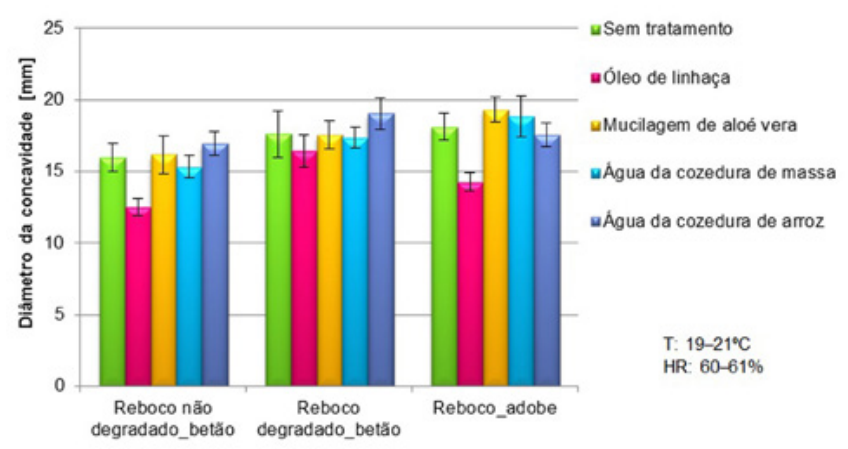

Figura 12. . Diâmetro da concavidade provocada pelo ensaio de impacto da esfera nos rebocos aplicados sobre os muretes experimentais antes e após a aplicação de tratamentos superficiais.

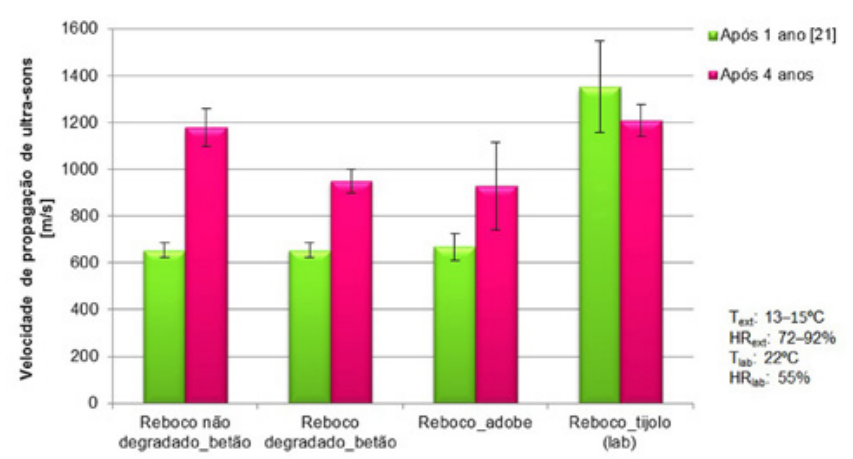

Figura 13. Velocidade de propagação de ultra-sons nos rebocos aplicados nos muretes experimentais e do tijolo furado, após um ano de exposição natural [21] e após quatro anos.

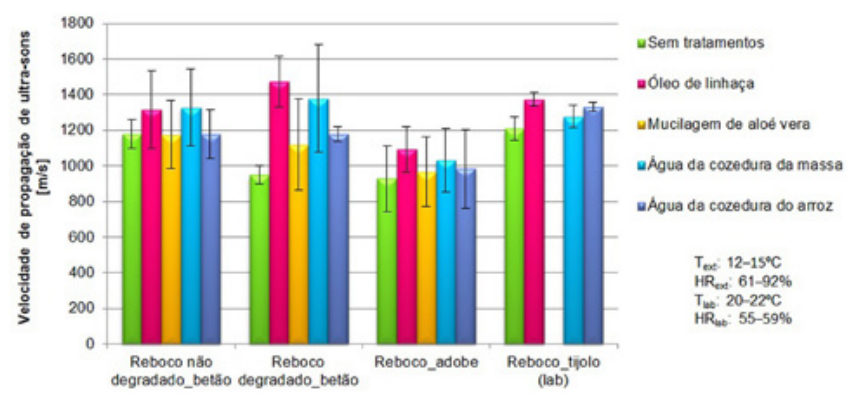

Figura 14. Velocidade de propagação de ultra-sons nos rebocos aplicados sobre os muretes experimentais e no tijolo furado, antes e após a aplicação de tratamentos superficiais. do reboco, obtidos após um ano [21] e após quatro anos de envelhecimento natural, são comparados na Figura 13.

Após a aplicação e secagem dos tratamentos superficiais sobre os rebocos aplicados nos muretes experimentais e no tijolo furado, em laboratório, foram realizados os ensaios de velocidade de propagação de ultra-sons, cujos valores médios e respectivos desvios-padrão, bem como os intervalos de temperatura e $\mathrm{HR}$ em que foram realizados os ensaios, são apresentados na Figura 14.

\section{Discussão de resultados}

A Tabela 3 apresenta uma comparação qualitativa dos resultados obtidos para cada tratamento superficial e para cada reboco e ensaio analisado.

\section{Alteração de cor}

Através da observação da Tabela 3 é possível concluir que o óleo de linhaça é o único tratamento de superfície que promove uma alteração de cor da superfície de reboco, escurecendo-o, ao contrário do que acontece com os restantes tratamentos. Esta alteração de cor poderá ser considerada uma desvantagem associada ao tratamento de superfície de óleo de linhaça, embora pouco significativa.

\section{Coesão superficial}

Da análise dos resultados de coesão superficial obtidos nos rebocos de argamassa de terra é possível concluir que, após quatro anos de exposição natural semi-protegida, existe um aumento da coesão superficial, isto é, menor perda de massa, do reboco aplicado sobre os muretes de alvenaria de adobe e de blocos de betão. No reboco aplicado sobre o murete de blocos de betão ocorreu maior perda de massa na zona degradada comparativamente à zona não degradada. Tal poderá estar relacionado com a degradação do reboco que apresenta ocorrência de erosão, levando a uma perda de finos argilosos à superfície, o que, por sua vez, promove uma presença mais acentuada de agregado, com massa superior e menor capacidade de coesão à superfície. O reboco de terra aplicado sobre o tijolo furado em laboratório também teve um acréscimo de coesão superficial, tendo ocorrido uma menor perda de massa. No entanto, considera-se que as variações de HR entre os períodos de ensaio podem justificar alguma variação relativamente à coesão.

Da análise da Tabela 3 é possível concluir que os tratamentos com óleo de linhaça e com a água de cozedura do arroz promovem a melhoria da coesão superficial em todos os rebocos, uma vez que apresentam as menores perdas de massa. O óleo de linhaça e a água de cozedura do arroz só não mostraram eficiência (tal como nenhum dos restantes tratamentos) no reboco não degradado aplicado sobre a alvenaria de blocos de betão. Pela análise visual, o resultado obtido com o óleo de linhaça já seria esperado, uma vez que este tratamento de superfície arrasta menor 
quantidade de partículas à superfície em comparação com os restantes, que são todos aquosos. É possível concluir que a utilização de mucilagem de aloé vera provoca um aumento de perda de massa, e consequente, a perda de coesão superficial, sendo o tratamento superficial que apresenta pior resultado. Com efeito, a aplicação dos tratamentos superficiais através de pincelagem, provocaram, como já referido, a libertação de alguns finos da superfície, podendo assim justificar a perda de coesão superficial dos rebocos após a aplicação de alguns tratamentos superficiais. Sugere-se assim, em estudos futuros, avaliar o efeito das aplicações dos tratamentos por aspersão.

No entanto, a aplicação da água de cozedura de arroz apresenta, como vantagem face ao óleo de linhaça, o facto de não produzir alteração de cor.

Santos et al. [6] obtiveram valores de perda de coesão de $0,2-0,5 \mathrm{~g}$, para argamassas de terra com areia lavada e não lavada com adição de cal aérea e cal hidráulica natural. As perdas de coesão obtidas nos rebocos de argamassa após um ano de exposição natural [18, 21] e após de quatro anos de exposição com e sem aplicação de tratamentos de superfície, analisadas no presente estudo, são inferiores aos valores obtidos por Santos et al. [6]. Apesar de, tanto as argamassas analisadas por Santos et al. [6] como as argamassas analisadas no presente estudo, se encontrarem em exposição natural na mesma zona de exposição, é importante referir que os melhores resultados obtidos pelas argamassas analisadas no presente estudo podem estar relacionados com o facto de apenas estas argamassas estarem protegidas da maior parte da chuva e do vento incidentes, ao contrário do que aconteceu com as argamassas de Santos et al. [6] que não tinham protecção superior.

Drdácký et al. [32] analisaram argamassas de cal aérea, utilizando o mesmo procedimento de ensaio, tendo obtido valores de perda de massa de $0,017-0,020 \mathrm{~g}$. Estes valores são inferiores quer aos obtidos no presente estudo, após quatro anos de exposição, com e sem aplicação de tratamentos de superfície, quer aos obtidos por Faria et al. [18] e Santos et al. [21], com um ano de exposição. A excepção é o caso do reboco não degradado aplicado sobre a alvenaria de blocos de betão sem tratamento de superfície após quatro anos de exposição e com a aplicação de óleo de linhaça, que apresentam perda de coesão de $0,007 \mathrm{~g}$ e $0,013 \mathrm{~g}$, respectivamente.

\section{Durezas superficiais por durómetro e por esclerómetro} Através da análise da Figura 8, é notório um aumento da dureza superficial dos rebocos aplicados nos muretes experimentais e no tijolo furado, em laboratório, após os

Tabela 3. Influência dos tratamentos de superfície nas características de cada reboco analisado: $\mathbf{\Delta}$ - Aumento da característica analisada; Diminuição da característica analisada; = - Mantem-se a característica analisada; - - Não avaliado; Verde - Melhoria da característica; Vermelho Agravamento da característica.

\begin{tabular}{|c|c|c|c|c|c|c|}
\hline & Cor & Coesão superficial & Durómetro & Esclerómetro & $\begin{array}{l}\text { Impacto da esfera } \\
\text { (concavidade) }\end{array}$ & Ultra-sons \\
\hline & \multicolumn{6}{|c|}{ Óleo de linhaça } \\
\hline Reboco não degradado - betão & $\boldsymbol{\Delta}$ & $\nabla$ & $\Delta$ & $=$ & $\nabla$ & $\Delta$ \\
\hline Reboco degradado - betão & $\Delta$ & $\Delta$ & $\Delta$ & $\nabla$ & $\nabla$ & $\Delta$ \\
\hline Reboco-adobe & $\Delta$ & $\Delta$ & $=$ & $\Delta$ & $\nabla$ & $\Delta$ \\
\hline \multirow[t]{2}{*}{ Reboco - tijolo furado (lab.) } & $\Delta$ & $=$ & $\Delta$ & - & - & $\Delta$ \\
\hline & \multicolumn{6}{|c|}{ Mucilagem de aloé vera } \\
\hline Reboco não degradado - betão & $=$ & $\nabla$ & $\nabla$ & $\Delta$ & $\Delta$ & $=$ \\
\hline Reboco degradado - betão & $=$ & $\nabla$ & $=$ & $\nabla$ & $=$ & $\Delta$ \\
\hline Reboco - adobe & $=$ & $\nabla$ & $\nabla$ & $=$ & $\Delta$ & $\Delta$ \\
\hline \multirow[t]{2}{*}{ Reboco - tijolo furado (lab.) } & $=$ & - & - & - & - & - \\
\hline & \multicolumn{6}{|c|}{ Água da cozedura de massa } \\
\hline Reboco não degradado - betão & $=$ & $\nabla$ & $=$ & $\Delta$ & $\nabla$ & $\boldsymbol{\Delta}$ \\
\hline Reboco degradado - betão & $=$ & $=$ & $\nabla$ & $\nabla$ & $\nabla$ & $\Delta$ \\
\hline Reboco - adobe & $=$ & $\Delta$ & $\nabla$ & $\Delta$ & $\Delta$ & $\Delta$ \\
\hline \multirow[t]{2}{*}{ Reboco - tijolo furado (lab.) } & $=$ & $\nabla$ & $=$ & - & - & $\Delta$ \\
\hline & \multicolumn{6}{|c|}{ Água da cozedura de arroz } \\
\hline Reboco não degradado - betão & $=$ & $\nabla$ & $\nabla$ & $\Delta$ & $\Delta$ & $=$ \\
\hline Reboco degradado - betão & $=$ & $\Delta$ & $=$ & $\nabla$ & $\Delta$ & $\Delta$ \\
\hline Reboco-adobe & $=$ & $\Delta$ & $\nabla$ & $\Delta$ & $\nabla$ & $\Delta$ \\
\hline
\end{tabular}


quatro anos de exposição natural dos rebocos. A excepção é o reboco aplicado sobre os blocos de betão na zona degradada, após quatro anos de exposição, que apresenta um valor ligeiramente inferior de dureza superficial por durómetro. $\mathrm{O}$ aumento da dureza superficial dos rebocos após a exposição natural poderá dever-se a uma possível diferença de humidade relativa ambiente nos períodos em que os ensaios foram realizados (após um e quatro anos) e/ou eventual bioconsolidação superficial ocorrida por organismos biológicos que possam existir nos suportes, na terra da argamassa original ou ter acedido ao reboco durante a sua exposição. A argamassa pré-doseada, aplicada em diferentes suportes e analisada em diferentes zonas, apresenta dureza superficial semelhante, tanto por durométro como por esclerómetro.

Após a aplicação dos tratamentos de superfície, é possível constatar, através da observação da Tabela 3, que o óleo de linhaça é o tratamento superficial que apresenta melhor dureza superficial por durómetro. Com a aplicação do óleo de linhaça a dureza superficial aumenta (ou mantém-se) em todos os rebocos, comparativamente com os restantes tratamentos de superfície aplicados. A aplicação de mucilagem de aloé vera e água da cozedura de massa e de arroz, conduziu, na maioria dos casos, a uma perda de dureza superficial por durómetro dos rebocos analisados. Esta perda de dureza superficial poderá estar relacionada com a aplicação por pincelagem do tratamento, uma vez que promove a deslocação de finos da superfície, e/ou a sua consistência ser um pouco mais fluída, que leva a uma degradação da superfície dos rebocos.

Relativamente à dureza superficial por esclerómetro após a aplicação dos tratamentos de superfície, verificou-se que, nenhum dos tratamentos foi eficaz no caso do reboco degradado sobre alvenaria de blocos de betão. Em todos os restantes casos os tratamentos melhoraram (ou mantiveram) a dureza superficial.

Santos et al. [21] obtiveram valores de dureza superficial por durómetro de 80-84 Shore A e por esclerómetro de 38-40 Vickers, como é possível observar na Figura 8. Após quatro anos, o reboco da mesma argamassa pré-doseada com a aplicação do óleo de linhaça apresenta valores superiores de dureza superficial por durómetro em todos os rebocos analisados. A aplicação da mucilagem de aloé vera e da água da cozedura de massa promove também um aumento da dureza superficial por durómetro quando aplicadas no reboco não degradado sobre os blocos de betão. No entanto, a água da cozedura de massa, quando aplicada sobre o reboco degradado sobre os blocos de betão, leva a uma diminuição da dureza superficial por durómetro relativamente à gama de valores obtida por Santos et al. [21]. Mais uma vez se refere que a perda de dureza superficial por durómetro destes rebocos após a aplicação dos tratamentos de superfície mencionados, pode estar relacionada com a perda de finos da superfície aquando da aplicação, através de pincelagem, dos tratamentos de superfície. Relativamente à dureza superficial por esclerómetro, todos os tratamentos superficiais sobre todos os rebocos analisados apresentam valores superiores aos obtidos por Santos et al. [21].

Santos et al. [6] analisaram, ao fim de dois anos, a dureza superficial por durómero e esclerómetro pendular de rebocos de argamassas de terra com a utilização de uma terra argilosa, diferente da utilizada no presente estudo, areia não lavada, com traço volumétrico de 1:3 (terra argilosa: areia), e areia lavada, com traço 1:2, assim como a adição de cal aérea CL9o e cal hidráulica natural NHL3,5 à argamassa de areia lavada, com traço volumétrico de 1:2. Enquanto que os valores de dureza superficial de durómetro de 69-79 Shore A e 38 Vickers de dureza superficial por esclerómetro, foram obtidos para as argamassas sem adição de cal, os valores de 50-70 Shore A e 25-42 Vickers, foram obtidos para as argamassas de areia lavada com adição de CL9o e de NHL3,5.

Os rebocos sem tratamento de superfície, analisados no presente estudo, apresentaram dureza superficial por durómetro e por esclerómetro um pouco superior aos valores obtidos por Santos et al. [6]. É possível observar que todos os rebocos tratados superficialmente ao fim de quatro anos de exposição apresentam dureza superficial superior aos rebocos analisados por Santos et al. [6], excepção feita para o reboco degradado aplicado sobre a alvenaria de blocos de betão com aplicação de água da cozedura de massa, que apresenta um valor de dureza superficial por durómetro dentro da gama de valores obtida por Santos et al. [6], para argamassa de terra sem adição de cal. É importante ter em consideração que os valores inferiores de dureza superficial apresentados pelos rebocos de argamassa com base em terra e com adição de CL9o e NHL3,5, analisados por Santos et al. [6], podem estar relacionados com uma maior degradação destes rebocos, devido ao facto de estarem mais expostos às condições ambientais (não estavam protegidos da chuva incidente).

A utilização de consolidantes para repor a coesão de argamassas de cal antigas foi analisada por Tavares et al. [40], que obteve uma dureza superficial de 59-68 Shore A e de 33 Vickers, respectivamente por durómetro e esclerómetro. Os valores de dureza superficial obtidos no presente estudo através da utilização das mesmas técnicas, são superiores aos obtidos por Tavares et al. [40]. Esta diferença poderá estar relacionada com uma maior degradação das argamassas de cal antiga utilizadas por Tavares et al. [40].

\section{Resistência ao impacto da esfera}

Após quatro anos de exposição natural, os rebocos de argamassa pré-doseada de terra apresentam uma resistência ao impacto da esfera superior àquela que foi obtida após um ano de exposição natural, uma vez que apresentam concavidade inferior. Esta baixa concavidade demonstra uma boa resistência superficial, que está em consonância com os resultados de dureza superficial por durómetro e esclerómetro (Figura 8), que apresentam valores superiores aos obtidos por Santos et al. [21]. 
Através da análise da Tabela 3, constata-se que o óleo de linhaça diminui o diâmetro da concavidade do impacto da esfera, ou seja, diminui a deformabilidade, e aumenta, por conseguinte, a resistência dos rebocos de argamassa de terra aplicados em todos suportes. No entanto, por não ocorrer fissuração, a deformabilidade considera-se aceitável, sendo assim o tratamento que, deste ponto de vista, apresenta melhores resultados. O tratamento com água da cozedura de massa apresenta um decréscimo do diâmetro da concavidade resultante do impacto da esfera nos rebocos aplicados sobre a alvenaria de blocos de betão. O tratamento com água da cozedura do arroz, apresenta, por sua vez, um decréscimo do diâmetro da concavidade no reboco aplicado sobre o adobe.

Santos et al. [6] obtiveram diâmetros da concavidade de $17-24 \mathrm{~mm}$, para argamassas de outra terra sem adição de ligantes com areia lavada e não lavada e com areia lavada com adição de CL9o e NHL3,5. No presente estudo, o reboco não degradado sobre os blocos de betão apresenta valores inferiores de diâmetro da concavidade, antes e após a aplicação dos tratamentos de superfície, indiciando assim menor deformabilidade e maior resistência mecânica, comparativamente às argamassas analisadas por Santos et al. [6]. Nos restantes casos, os valores de diâmetro da concavidade encontram-se no mesmo intervalo de valores obtido por Santos et al. [6], à excepção dos rebocos com a aplicação do óleo de linhaça, que apresentam valores inferiores de deformabilidade e, consequentemente, maior resistência mecânica.

Santos et al. [6] não registaram a HR do ar no decorrer do ensaio. É importante referir que diferentes humidades relativas do ar no decorrer da exposição dos rebocos, antes e durante o ensaio, podem levar a diferentes valores de deformabilidade por impacto da esfera da argamassa, devido à capacidade higroscópica da argila e à plasticidade das argamassas de terra quando em contacto com humidade. Este pode ser um dos factores que poderá justificar a maior deformabilidade por impacto da esfera das argamassas analisadas por Santos et al. [6].

$\mathrm{Na}$ análise de rebocos com a adição de vários ligantes, como a cal hidráulica e cimentos, pozolanas naturais, sílica de fumo e metacaulino, aplicados em painéis exteriores após 6 e 14 semanas, Veiga et al. [39] obtiveram valores de diâmetro da concavidade de $10-16 \mathrm{~mm}$. No presente estudo, todos os rebocos sem e com aplicação dos tratamentos de superfície, apresentaram diâmetro de concavidade superior aos obtidos por Veiga et al. [39], excepção feita para o reboco não degradado sobre a alvenaria de blocos de betão, sem e com aplicação de óleo de linhaça e água da cozedura de massa, e do reboco sobre a alvenaria de adobe com aplicação de óleo de linhaça, que apresentaram diâmetro da concavidade semelhantes aos de Veiga et al. [39]. A maior deformabilidade das argamassas de terra quando comparadas com argamassas de cal hidráulica e de cimento justifica os valores superiores de deformabilidade por impacto da esfera obtidos no presente estudo. É possível concluir que a aplicação de óleo de linhaça reduz a deformabilidade por impacto da esfera da argamassa de terra analisada, para valores semelhantes aos obtidos em argamassas de cal hidráulica e de cimento.

\section{Velocidade de propagação de ultra-sons}

Pela análise dos resultados da velocidade de propagação de ultra-sons, obtidos após um e quatro anos de exposição natural (Figura 13), é notório um aumento dessa velocidade nos rebocos aplicados nos muretes experimentais e uma diminuição na aplicação em tijolo furado (em laboratório). Um aumento da velocidade de propagação dos ultra-sons após os quatro anos de exposição natural dos rebocos indica um aumento da compacidade destes rebocos, quando aplicados no exterior. Estes resultados não denunciam a presença de fissuração no seio do reboco. A elevada velocidade de propagação dos ultra-sons apresentada pelo reboco não degradado aplicado sobre os blocos de betão, não demonstrou a presença de nenhum tipo de fissuração, uma vez que o ensaio foi realizado numa zona não fissurada.

É possível concluir, através da Tabela 3, que as aplicações dos tratamentos superficiais aumentam a velocidade de propagação de ultra-sons de todos os rebocos, e, por conseguinte, a sua compacidade. A excepção é o tratamento com mucilagem de aloé vera, que diminui ligeiramente a velocidade de propagação dos ultra-sons quando aplicado sobre o reboco não degradado no murete de blocos de betão. Este resultado pode estar relacionado com a fissuração já existente neste reboco antes da aplicação dos tratamentos de superfície. O maior ou menor aumento da velocidade de propagação dos ultra-sons obtido pelos diferentes tratamentos de superfície analisados pode dever-se principalmente à espessura de penetração de cada tratamento na camada de reboco, que não foi avaliada neste estudo.

Faria et al. [41] analisou argamassas de cal aérea CL90-S com traço volumétrico de 1:2 e 1:3, com substituição de $25 \%$ de cal aérea por terra e $10 \%$ de areia fina por terra, respectivamente, tendo obtido valores de velocidade de propagação de ultra-sons de $918-1016 \mathrm{~m} / \mathrm{s}$ para rebocos aplicados sobre tijolo furado em laboratório e $551-775 \mathrm{~m} / \mathrm{s}$ para rebocos aplicados in situ sobre taipa. Os valores de velocidade de propagação de ultra-sons obtidos no presente estudo são superiores aos obtidos por Faria et al. [41] para os rebocos aplicados sobre taipa. Comparando os valores obtidos por Faria et al. [41] para os rebocos aplicados sobre o tijolo, apenas o reboco degradado sem tratamento de superfície e os rebocos sem tratamento de superfície e com a aplicação de mucilagem de aloé vera e de água da cozedura de arroz aplicados sobre a alvenaria de adobe, apresentam valores dentro da gama obtida por estes autores. Os restantes apresentam valores superiores. É importante referir que, ao contrário dos rebocos e argamassa analisados por Faria et al. [41], os rebocos analisados no presente estudo foram protegidos da chuva e do vento incidente. 


\section{Conclusões}

Da avaliação da durabilidade do reboco de argamassa prédoseada de terra analisada no presente estudo após quatro anos de exposição natural, é possível concluir que não ocorreu destacamento nem aparente perda de aderência do reboco ao suporte, nem desenvolvimento biológico, como fungos, bolores ou vegetação parasitária, à superfície do reboco, isto apesar da argamassa conter fibras vegetais na sua composição. Foi notória uma pequena alteração da cor do reboco, justificada pela ligeira erosão ocorrida à superfície que leva a uma perda de finos argilosos (de cor avermelhada) e pela maior exposição da areia e das fibras vegetais que o constituem (de cor mais clara). Foi observada a ocorrência de pequenas fissuras no reboco de terra aplicado sobre a alvenaria de blocos de betão comparativamente à aplicação sobre alvenaria de adobe. Sendo o reboco de terra não estabilizado com ligante, para a eliminação dessas fissuras bastaria realizar um humedecimento superficial do reboco e novo aperto, o que não foi efectuado neste caso.

A aplicação dos tratamentos de superfície levou à melhoria da coesão superficial dos rebocos, excepto no caso da aplicação da mucilagem de aloé vera e da água da cozedura de massa (que apenas apresentaram melhoria da coesão superficial quando aplicado sobre o reboco aplicado no murete de adobe). Este comportamento da mucilagem de aloé vera e da água da cozedura de massa pode ser justificado pela perda de finos devido à aplicação por pincelagem dos tratamentos de superfície, com arrastamento de partículas, que acabam por ficar menos coesas.

Foi notório um aumento da dureza superficial dos rebocos, dentro de limites aceitáveis, determinada pela diminuição do diâmetro da concavidade no ensaio de impacto da esfera, sem aparecimento de fissuras nem destacamento do reboco, e pelo esclerómetro, à excepção dos tratamentos aplicados sobre o reboco degradado sobre o murete de blocos de betão. A aplicação do óleo de linhaça melhorou a dureza superficial por durómetro em todos os rebocos. O decréscimo da dureza superficial por durómetro dos rebocos tratados com água de cozedura pode ser relacionado com a perda de finos na superfície do reboco, por sua vez causada pela aplicação dos tratamentos de superfície.

Os resultados da velocidade de propagação dos ultrasons, obtidos após um e quatro anos de exposição, indiciam um aumento da compacidade dos rebocos aplicados sobre os muretes experimentais. Esta melhoria é também verificada após a aplicação dos tratamentos de superfície, o que pode dever-se à diferenciada espessura de penetração de cada tratamento de superfície na camada de reboco. A espessura de penetração dos tratamentos pode também depender do modo de aplicação. Aliado à pequena degradação ocorrida na superfície dos rebocos causada pela aplicação dos tratamentos de superfície por pincelagem, deve ser avaliada, futuramente, a aplicação destes tratamentos por aspersão e a determinação da espessura de penetração atingida.
A aplicação do óleo de linhaça mostrou, assim, ser uma boa hipótese de tratamento superficial ecológico a aplicar sobre os rebocos de argamassa de terra, uma vez que, de entre os tratamentos de superfície analisados, foi o que apresentou melhores características. Foi facilmente aplicado por pincelagem e não provocou arrastamento de finos. Embora a aplicação do óleo de linhaça como tratamento de superfície tenha como desvantagem a alteração de cor da superfície do reboco, para um tom mais escuro, este mostrou ser eficiente na protecção do reboco de terra, independentemente do suporte em questão, pelo que se recomenda a sua utilização em rebocos de terra com exposição à água ou a abrasão mecânica. Estudos futuros avaliarão se o efeito de protecção do óleo de linhaça é durável com o envelhecimento natural e em laboratório.

\section{Agradecimentos}

Agradece-se a disponibilização da argamassa pré-doseada de terra à empresa EMBARRO e ao Eng. Vítor Silva da FCT NOVA pelo apoio prestado na aplicação dos rebocos e durante a campanha experimental. Este trabalho insere-se nos projectos financiados por fundos nacionais da Fundação para a Ciência e Tecnologia PTDC/EPH-PAT/4684/2014: DB-Heritage - Base de dados de materiais de construção com interesse histórico e patrimonial e SAICT/23349/2016: INDEEd - Regulação da qualidade do ar interior através da utilização de argamassas ecoeficientes. Este último é também financiado pelo Programa Operacional Competitividade e Internacionalização (COMPETE 2020), por fundos FEDER através dos Programas Operacionais Regionais de Lisboa e do Centro (Lisboa 2020, Centro 2020).

\section{REFERÊNCIAS}

1. Bruno, P.; Faria,P.; Candeias, A.; Mirão, J., 'Earth mortars from on pre-historic habitat settlements in south Portugal. Case studies', Journal of Iberian Archaeology 13 (2010) 51-67, http://hdl. handle.net/10362/9954.

2. Emiroğlu, M.; Yalama, A.; Erdoğdu, Y., 'Performance of readymixed clay plasters produced with different clay/sand ratios', Applied Clay Science 115 (2015) 221-229, https://doi.org/10.1016/j. clay.2015.08.005.

3. Niroumand, H.; Kibert, C. J.; Barcelo, J. A.; Saaly, M., 'Contribution of national guidelines in industry growth of earth architecture and earth buildings as a vernacular architecture', Renewable and Sustainable Energy Reviews $\mathbf{7 4}$ (2017) 1108-1118, https://doi.org/10.1016/j.rser.2017.02.074.

4. Cantù, M.; Giacometti, F.; Landi, A. G.; Riccardi, M. P.; Tarantino, S. C; Grimoldi, A., 'Characterization of XVIIIth century earthen mortars from Cremona (Northen Italy): Insights on a manufacturing tradition', Materials Characterization 103 (2015) 81-89, https://doi.org/10.1016/j. matchar.2015.03.018.

5. Gomes, M. I.; Faria, P.; Gonçalves, T. D., 'Earth-based mortars for repair and protection of rammed earth walls. Stabilization with mineral binders and fibers', Journal of Cleaner

Production 172 (2018) 2401-2414, https://doi.org/10.1016/j. jclepro.2017.11.170.

6. Santos, T.; Faria, P.; Santos Silva, A., 'Avaliação in situ do comportamento de rebocos exteriores de argamassas de terra com baixas adições de cais', Conservar Património 26 (2017) 1121, https://doi.org/10.14568/cp2016022. 
7. Morton, T., Earth masonry. Design and Construction Guideline, IHS BRE Press, Bracknell (2008).

8. Minke, G., Building with Earth. Design and Technology of a Sustainable Architecture, WITpress, Berlin (2006).

9. Mèlia, P.; Ruggieri, G.; Sabbadini, S.; Dotelli, G., 'Environmental impacts of natural and conventional building materials: a case study on earth plasters', Journal of Cleaner Production 80 (2014) 176-186, https://doi.org/10.1016/j. jclepro.2014.05.073.

10. Cagnon, H.; Aubert, J. E.; Coutand, M.; Magniont, C., 'Hygrothermal properties of earth bricks', Energy and Buildings 80 (2014) 208-217, https://doi.org/10.1016/j. enbuild.2014.05.024.

11. Lima. J.; Faria, P.; Santos Silva, A., 'Earthen plasters based on illitic soils from Barrocal region of Algarve: contributions for building performance and sustainability', Key Engineering Materials 678 (2016) 64-77, https://doi.org/10.4028/www. scientific.net/KEM.678.64.

12. Ashour, T.; Georg, H.; Wu, W., 'An experimental investigation on equilibrium moisture content of earth plaster with natural reinforcement fibres for straw bale buildings', Applied Thermal Engineering 31 (2011) 293-303, https://doi.org/10.1016/j. applthermaleng.2010.09.009.

13. Liuzzi, S.; Stefanizzi, P., 'Experimental investigation on lightweight and lime stabilized earth composites', Key Engineering Materials 666 (2016) 31-45, https://doi.org/10.4028/ www.scientific.net/KEM.666.31.

14. Randazzo, L.; Montana, G.; Hein, A.; Castiglia, A.; Rodonò, G.; Donato, D. I., 'Moisture absorption, thermal conductivity and noise mitigation of clay based plasters: the influence of mineralogical and textural characteristics', Applied Clay Science 132-133 (2016) 498-507, https://doi.org/10.1016/j. clay.2016.07.021.

15. Bruno, A. W.; Gallipoli, D.; Perlot, C.; Mendes, J., 'Effect of stabilisation on mechanical properties, moisture buffering and water durability of hypercompacted earth', Construction and Building Materials 149 (2017) 733-740, https://doi. org/10.1016/j.conbuildmat.2017.05.182.

16. Maskell, D.; Thomson, A.; Walker, P.; Lemke, M., 'Determination of optimal plaster thickness for moisture buffering of indoor air', Building and Environment 130 (2018) 143-150, https://doi.org/10.1016/j.buildenv.2017.11.045.

17. Faria, P.; Lima, J., Rebocos de terra, Cadernos de Construção com Terra 3, Argumentum, Lisboa (2018).

18. Faria, P.; Santos, T.; Aubert, J. E., 'Experimental characterization of an earth eco-efficient plastering mortar', Journal of Materials in Civil Engineering 28(1) (2016), https://doi. org/10.1061/(ASCE)MT.1943-5533.0001363.

19. Santos, T.; Nunes, L.; Faria, P., 'Production of eco-efficient earth-based plasters: Influence of composition on physical performance and bio-susceptibility', Journal of Cleaner Production 167 (2017) 55-67, https://doi.org/10.1016/j. jclepro.2017.08.131.

20. Delinière, R.; Aubert, J. E.; Rojat, F.; Gasc-Barbier, M., 'Physical, mineralogical and mechanical characterization of ready-mixed clay plaster', Building and Environment 80 (2014) 11-17, https://doi.org/10.1016/j.buildenv.2014.05.012.

21. Santos, T.; Faria, P.; Silva, V., 'Can an earth plaster be efficient when applied on different masonries?', Journal of Building
Engineering 23 (2019) 314-323, https://doi.org/10.1016/j. jobe.2019.02.011.

22. Stazi, F.; Nacci, A.; Tittarelli, F.; Pasqualini, E.; Munafò, P., 'An experimental study on earth plasters for earthen building protection: The effects of different admixtures and surface treatments', Journal of Cultural Heritage 17 (2016) 27-41, https:// doi.org/10.1016/j.culher.2015.07.009.

23. Matero, F. 'Mud brick metaphysics and the preservation of earthen ruins', Conservation and Management of Archaeological Sites 17(3) (2015) 209-223, https://doi.org/10.1080/13505033.201 5.1129798 .

24. Vissac, A.; Bourgès, A.; Gandreau, D.; Anger, R.; Fontaine, L., Argiles \& biopolymers. Les stabilisants naturels pour la construction en terre, CRAterre, Villefontaine (2017).

25. Lima, J.; Silva, S.; Faria, P., 'Rebocos de terra: Influência da adição de óleo de linhaça e comparação com rebocos convencionais', em TEST\&E 2016 - Ensaiar para Reabilitar, Atas do $1^{\circ}$ Congresso de Ensaios e Experimentação em Engenharia Civil, Lisboa, Portugal (2016), https://doi.org/10.5281/zenodo.164637.

26. Kita, Y., 'The functions of vegetable mucilage in lime and earth mortars - A review', em HMC2013 - 3rd Historic Mortars Conference (CD), Glasgow, Escócia (2013).

27. NP EN 1097-3, Ensaios para determinação das propriedades mecânicas e físicas dos agregados. Parte 3: Método para determinação da massa volúmica e dos vazios. IPQ, Caparica, Portugal (2000).

28. EN 1015-3, Methods of test for mortar for masonry. Part 3: Determination of consistence of fresh mortar (by flow table), CEN, Bruxelas, Bélgica (1999).

29. EN 1015-6, Methods of test for mortar for masonry. Part 6: Determination of bulk density offresh mortar, CEN, Bruxelas, Bélgica (2006).

30. EN 1015-7, Methods of test for mortar for masonry. Part 7: Determination of air content of fresh mortar, CEN, Bruxelas, Bélgica (1998).

31. DIN 18947, Earth plasters. Terms and definitions, requirements, test methods, Deutsches Institut für Normung EV, Berlim, Alemanha (2013).

32. Drdácky, M.; Lesák, J.; Niedoba, K.; Valach, J., 'Peeling tests for assessing the cohesion and consolidation characteristics of mortar and render surfaces', Materials and Structures 48 (2014) 1947-1963, https://doi.org/10.1617/s11527-014-0285-8.

33. ASTM D2240, Standard test method for rubber propertydurometer hardness, ASTM Standards, United States of America (2000).

34. ASTM C805, Standard test method for rebound hammer of hardened concrete, ASTM Standards, United Sates of America (2008).

35. FE Pa 25, Ficha de ensaio para revestimentos de paredes - Ensaio de choque da esfera, LNEC, Lisboa, Portugal (1980).

36. FE Pa 43, Ficha de ensaio para revestimentos de paredes - Ensaio de avaliação de características mecânicas por ultra-sons, LNEC, Lisboa, Portugal (2010).

37. NP EN 12504-4, Ensaios de betão nas estruturas. Parte 4: Determinação da velocidade de propagação dos ultra-sons, IPQ Caparica, Portugal (2007).

38. Malanho, S.; Veiga, R., 'Análise do comportamento mecânico em laboratório e in situ de revestimentos pré-doseados de cimento', em $3^{\circ}$ Congresso Português de Argamassas de Construção, APFAC (CD), Lisboa, Portugal (2010). 
39. Veiga, M. R.; Velosa, A.; Magalhães, A., 'Experimental applications of mortars with pozzolanic additions: Characterization and performance evaluation', Construction and Building Materials 23 (2009) 318-327, https://doi. org/10.1016/j.conbuildmat.2007.12.003.

40. Tavares, M.; Veiga, M. R.; Fragata, A., 'Conservation of old renderings - the consolidation of rendering with loss of cohesion', em HMC2008 - 1st Historical Mortars Conference (CD), Lisboa, Portugal (2008).

41. Faria, P.; Silva, V.; Jamú, N.; Dias, I., 'Evaluation of air lime and clayish earth mortars for earthen wall renders', em Vernacular Heritage and Earthen Architecture: Contributions for Sustainable Development, ed. M. Correia, G. Carlos, S. Rocha, CRC Press/ Taylor \& Francis Group, London, UK (2014) 407-413.
RECEBIDO: 2019.3.1

REVISTO: 2019.4.17

ACEITE: 2019.10.20

ONLINE: 2020.4 .15

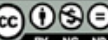

Licenciado sob uma Licença Creative Commons Atribuição-NãoComercial-SemDerivações 4.0 Internacional Para ver uma cópia desta licença, visite

http://creativecommons.org/licenses/by-nc-nd/4.o/deed.pt. 